\title{
Comparison of Strength and Endurance between Open and Closed Kinematic Chain Exercises after Anterior Cruciate Ligament Reconstruction: Randomized Control Trial
}

\author{
Hyungkyu Kang, MSc, PT ${ }^{1)}$, Jinhwa Jung, PhD, OT ${ }^{2)}$, Jaeho Yu, PhD, PT ${ }^{3)}$ \\ 1) Department of Physical Therapy, Sahmyook University \\ 2) Department of Occupational Therapy, Semyung University \\ 3) Department of Physical Therapy, Kangwon National University: 3 Hwangjo-ri, Dogye-eup, \\ Samcheok-si, Gangwon-do, 245-907, Republic of Korea. TEL: +82 033-540-3370, FAX: +82 033-540- \\ 3379,E-mail:naresa@empal.com
}

\begin{abstract}
Purpose] The purpose of this study was to compare the strength and endurance between open and closed kinematic chain exercises after anterior cruciate ligament reconstruction. [Subjects] Sixty-two subjects actively participating in rehabilitation for anterior cruciate ligament reconstruction for the last 3 month were chosen. Twenty-six subjects were excluded and consequently, the data of 36 subjects were analyzed. The participants were randomly divided into 2 groups for open or closed kinematic chain exercise. [Methods] Open or closed kinematic chain exercises were performed under direct supervision of 3 physical therapists for 30 minutes per session, 3 times a week for 12 weeks. Before and after the intervention, isokinetic strength, endurance, and squat strength were tested. [Results] In the comparison of the before and after exercise results, all variables showed significant differences. Open kinematic chain exercises resulted in a significantly greater gain in isokinetic strength and endurance of the extensor muscles than the closed kinematic chain exercises. [Conclusion] Open kinematic chain exercise is helpful for the development of strength and endurance of the knee extensor mechanism after anterior cruciate ligament reconstruction, and can be used effectively in a rehabilitation program.

Key words: Open kinematic chain, Closed kinematic chain, ACL reconstruction
\end{abstract}

(This article was submitted May 16, 2012, and was accepted Jun. 7, 2012)

\section{INTRODUCTION}

Anterior cruciate ligament (ACL) injury is a common cause of knee instability and alters the kinematics of the knee. An ACL injury typically occurs during the landing portion of a jump in ordinary sports activities and has a greater incidence in women than in men ${ }^{1,2)}$. ACL deficiency may lead to degenerative changes such as tears of the meniscus. Furthermore, meniscus damage may be correlated to an increased incidence of knee arthrosis ${ }^{3)}$. Knee instability following ACL injury results in various negative factors, which can be circumvented using ACL reconstruction. Even though structural instability can be corrected by surgery, fitness-related factors such as muscle strength, endurance, flexibility, and balance, must be corrected using therapeutic exercise in a rehabilitation setting ${ }^{4)}$.

After ACL injury, strengthening exercise for the surrounding muscles are differentiated as open kinematic chain $(\mathrm{OKC})$ or closed kinematic chain $(\mathrm{CKC})$ exercise. In OKC exercises, the distal segment, or foot, is free to move. In CKC exercises, the foot is fixed against an object producing movements in the proximal segments ${ }^{5}$. CKC exercise decreases the anterior shearing force of the tibia, increases hamstring involvement, increases tibiofemoral compressive forces, and decreases patellofemoral complications. Thus, $\mathrm{CKC}$ exercises are considered to be safer than OKC exercises ${ }^{6,7)}$. In early rehabilitation, CKC exercises are generally used to optimize safety while OKC exercises are avoided ${ }^{8,9)}$. However, recent studies have reported that, $\mathrm{OKC}$ exercises result in greater strength gain than $\mathrm{CKC}$ exercises in patients with ACL deficiency.

A controversial issue in ACL rehabilitation is the effects of $\mathrm{OKC}$ and $\mathrm{CKC}$ exercises. The present study compared isokinetic strength after $\mathrm{OKC}$ and $\mathrm{CKC}$ exercises in patients with ACL deficiency. However, for patients to complete activities of daily living (ADL), endurance is also an important factor, and it has not yet been measured. Most studies comparing between $\mathrm{OKC}$ and $\mathrm{CKC}$ have focused only on knee extensor muscles even though knee flexor muscles also contribute to knee joint movement. In addition, current experiments target patients with ACL deficiency and may not accurately represent patients who have received ACL reconstruction. As surgery methods for ACL reconstruction improve, physical therapists continue to look for optimal therapeutic exercises in an effort to modernize the rehabilitation program. Thus, this study aimed to compare 
1056 J. Phys. Ther. Sci. Vol. 24, No. 10, 2012

Table 1. General characteristics

\begin{tabular}{ccccc}
\hline Group & $\begin{array}{c}\text { Gender } \\
(\text { male/female })\end{array}$ & $\begin{array}{c}\text { Age } \\
(\text { year })\end{array}$ & $\begin{array}{c}\text { Height } \\
(\mathrm{cm})\end{array}$ & $\begin{array}{c}\text { Weight } \\
(\mathrm{kg})\end{array}$ \\
\hline OKC $(\mathrm{N}=18)$ & $12 / 6$ & $29.9 \pm 2.3$ & $172.6 \pm 7.6$ & $67.8 \pm 13.7$ \\
$\mathrm{CKC}(\mathrm{N}=18)$ & $12 / 6$ & $29.0 \pm 4.0$ & $172.6 \pm 8.5$ & $69.0 \pm 11.8$ \\
\hline
\end{tabular}

Note. All variables are mean \pm standard division. OKC; open kinematic chain. CKC; closed kinematic chain.

Table 2. Comparison of isokinetic strength, endurance and squat

\begin{tabular}{llrrrr}
\hline & & \multicolumn{2}{c}{ Before } & \multicolumn{2}{c}{ After } \\
\cline { 3 - 6 } & & OKC & \multicolumn{1}{c}{ CKC } & OKC & CKC \\
\hline Isokinetic strength & Extensor ${ }^{\#}$ & $72.3 \pm 30.5$ & $80.9 \pm 31.9$ & $118.8 \pm 29.6^{*}$ & $98.1 \pm 26.6^{*}$ \\
$\left(60^{\circ} / \mathrm{sec}, \mathrm{lb}\right.$-ft $)$ & Flexor & $35.9 \pm 21.0$ & $30.9 \pm 19.3$ & $69.5 \pm 25.7^{*}$ & $55.6 \pm 21.4^{*}$ \\
\hline Isokinetic endurance & Extensor ${ }^{\#}$ & $46.9 \pm 24.5$ & $44.7 \pm 20.4$ & $80.4 \pm 21.8^{*}$ & $64.9 \pm 18.2^{*}$ \\
$\left(180^{\circ} / \mathrm{sec}, \mathrm{lb}-\mathrm{ft}\right)$ & Flexor & $19.7 \pm 14.7$ & $12.1 \pm 13.6$ & $51.2 \pm 15.9^{*}$ & $40.8 \pm 14.9^{*}$ \\
\hline Squat $(\mathrm{kg})$ & & $136.1 \pm 29.5$ & $128.9 \pm 27.6$ & $164.7 \pm 24.4^{*}$ & $155.1 \pm 20.2^{*}$ \\
\hline
\end{tabular}

Note. All variables are mean \pm standard division. OKC; open kinematic chain. CKC; closed kinematic chain. RM; repetition maximum. ${ }^{*}$ significant difference between before and after $(\mathrm{p}<0.05) .{ }^{*}$ significant difference between OKC and $\mathrm{CKC}(\mathrm{p}<0.05)$

the strength and endurance benefits of $\mathrm{OKC}$ and $\mathrm{CKC}$ exercise therapies after ACL reconstruction.

\section{SUBJECTS AND METHODS}

A prospective, single-blind, randomized controlled study was performed. Sixty-two subjects who had been participating in a 3-month rehabilitation therapy for ACL reconstruction between May 2009 and October 2011 at a sports clinic in Korea were chosen for the study. Two subjects with orthopedic or neurological problems and 24 subjects who did not receive intervention in the previous 12 weeks were excluded. We analyzed the resulting data obtained from the remaining 36 subjects. Before starting the experiment, we obtained informed consent from all the subjects, then randomly divided them into 2 groups using computerized allocation for receipt of either OKC or CKC exercises. The general characteristics of the participants of each group are shown in Table 1. The study was singleblind, with each group performing each activity at a different time. OKC and $\mathrm{CKC}$ exercises were performed under direct supervision of 3 professional physical therapists for 30 minutes, 3 times a week for 12 weeks. A stationary bike was used for a 5-minute warm up and cool down. All exercises were done in 5 sets of 12 repetitions each at $70 \%$ intensity of 1 repetition maximum (RM). The resting time between sets was 30 seconds. OKC exercises were composed of the straight leg raise, leg extension, and leg curl, while CKC exercises were composed of the squat, leg press, and lunge. Before and after each intervention, we tested isokinetic strength, endurance, and squat strength. These tests were completed under the supervision of 2 physical therapists. To measure isokinetic strength and endurance, the Biodex System III (Biodex, USA) was used. For the measurement of strength, the knee joint was moved from $0^{\circ}$ to $90^{\circ}$ at a speed of $60^{\circ} \mathrm{s}$ in 4 forced repetitions to obtain peak torque. To measure endurance, we repeated the strength test at a speed of 180 degree/second 20 times to get the average power. We minimized the compensatory movement of the subjects by fixing the trunk to the chair with a belt and instructed the subjects to fold both arms. The squat test measured $1 \mathrm{RM}$ of the injured leg using leg press equipment (Sports Art, USA).

SPSS (v. 12.0) was used to calculate the averages and standard deviations of our data. Descriptive statistics was used to analyze the general characteristics of the subjects. Isokinetic strength, endurance, and squat strength differences between before and after exercise therapy were tested using the paired t-test. The differences between before and after therapy in isokinetic strength, endurance, and squat strength between the 2 groups were tested using the independent t-test. For all data, statistical significance was accepted at values of $\mathrm{p}<0.05$.

\section{RESULTS}

Isokinetic strength, endurance, and squat strength differences are shown in Table 2. In the comparison of before and after exercise therapy results, all outcome measures showed significant differences $(\mathrm{p}<0.05)$. OKC exercises showed a significantly greater difference in isokinetic strength and endurance of the extensor muscles than $\mathrm{CKC}$ exercises $(\mathrm{p}<0.05)$.

\section{DISCUSSION}

The purpose of this study was to investigate the differences in strength and endurance of patients who performed $\mathrm{OKC}$ or $\mathrm{CKC}$ exercises after ACL reconstruction. OKC exercise produces greater anterior shearing force than does CKC exercise, particularly during knee extension from $30^{\circ}$ to $0^{\circ}$. Accordingly, this increased shearing force can cause secondary instability and increase tension in the newly 
reconstructed $\mathrm{ACL}^{10-12)}$. For this reason, previous studies regarded $\mathrm{OKC}$ exercises in a negative light for patients with ACL deficiency. CKC exercises were commonly thought to be safer for use in ACL rehabilitation programs. However, currently, rehabilitation programs are changing in response to the changing methods of ACL reconstruction, such as the double-bundle allograft. Rehabilitation programs focus more on safety in the area of structural tightness and prevention of re-injury. It is important to find a more effective therapeutic exercise than to place emphasis on the safety of structural solidity. Thus, after testing $\mathrm{OKC}$ and $\mathrm{CKC}$ exercises on patients with ACL deficiency, Tagesson et al. reported that $\mathrm{OKC}$ exercise is more effective at strengthening the quadriceps than $\mathrm{CKC}$ exercise ${ }^{13)}$. However, their experiment did not measure the endurance of the flexor muscles, which is a critical factor for long distance walking. We have included measure in our present study of subjects with ACL reconstruction.

The results of our present study indicate that after OKC and $\mathrm{CKC}$ exercises, all outcome measures showed significant improvements, with $\mathrm{OKC}$ exercises being more effective at increasing the isokinetic strength and endurance of the extensor muscles. The function of knee extensors after ACL reconstruction is a critical factor in a patient's ability to overcome the injury ${ }^{14)}$. Therefore, it is very important to regain the strength of the quadriceps after ACL reconstruction. The results of the present experiment indicate that OKC exercise is more useful than CKC exercise after ACL reconstruction for increasing strength and endurance, and that it can be used effectively during therapeutic exercise programs. In the long term, continuous performance of OKC exercises after the end of therapy may be helpful for increasing endurance in activities such as long distance walking and stair climbing. Approximately 1 year after ACL reconstruction, even without special rehabilitation, the strength of the knee flexors increases, followed by an increase in ADL performance, whereas the strength of the knee extensor dose not increase ${ }^{15,16)}$. Thus, rehabilitation is critical for increase of the strength and endurance of the quadriceps.

In the present experiment, OKC exercises increased both the strength and endurance, as measured by the isokinetic test. In contrast, the $\mathrm{CKC}$ exercises, as measured by the squat strength test, did not result in an increase in strength or endurance. The squat movement is made by co-contraction between knee extensors and flexors. In the current study, the strength of the knee flexor did not differ significantly between $\mathrm{OKC}$ and $\mathrm{CKC}$, and this result might have affected the $\mathrm{CKC}$ results, which indicates that there were no significant increases in squat strength or endurance. We conclude that OKC exercises are helpful for the development of the strength and endurance of knee extensors after ACL reconstruction, and that they can be used effectively in rehabilitation programs.

\section{REFERENCES}

1) Pappas E, Zampeli F, Xergia SA, et al.: Lessons learned from the last 20 years of ACL-related in vivo-biomechanics research of the knee joint. Knee Surg Sports Traumatol Arthrosc, 2012.

2) Beaulieu ML, McLean SG: Sex-dimorphic landing mechanics and their role within the noncontact ACL injury mechanism: evidence, limitations and directions. Sports Med Arthrosc Rehabil Ther Technol, 2012, 4: 10. [Medline] [CrossRef]

3) Anstey DE, Heyworth BE, Price MD, et al.: Effect of timing of acl reconstruction in surgery and development of meniscal and chondral lesions. Phys Sportsmed, 2012, 40: 36-40. [Medline] [CrossRef]

4) Beynnon BD, Johnson RJ, Naud S, et al.: Accelerated versus nonaccelerated rehabilitation after anterior cruciate ligament reconstruction: a prospective, randomized, double-blind investigation evaluating knee joint laxity using roentgen stereophotogrammetric analysis. Am J Sports Med, 2011, 39: 2536-2548. [Medline] [CrossRef]

5) Fitzgerald GK: Open versus closed kinetic chain exercise: issues in rehabilitation after anterior cruciate ligament reconstructive surgery. Phys Ther, 1997, 77: 1747-1754. [Medline]

6) Henriksson M, Rockborn P, Good L: Range of motion training in brace vs. plaster immobilization after anterior cruciate ligament reconstruction: a prospective randomized comparison with a 2-year follow-up. Scand J Med Sci Sports, 2002, 12: 73-80. [Medline] [CrossRef]

7) Glass R, Waddell J, Hoogenboom B: The effects of open versus closed kinetic chain exercises on patients with ACL deficient or reconstructed knees: a systematic review. N Am J Sports Phys Ther, 2010, 5: 74-84. [Medline]

8) Bynum EB, Barrack RL, Alexander AH: Open versus closed chain kinetic exercises after anterior cruciate ligament reconstruction. A prospective randomized study. Am J Sports Med, 1995, 23: 401-406. [Medline] [CrossRef]

9) Fleming BC, Oksendahl H, Beynnon BD: Open- or closed-kinetic chain exercises after anterior cruciate ligament reconstruction? Exerc Sport Sci Rev, 2005, 33: 134-140. [Medline] [CrossRef]

10) Torzilli PA, Deng X, Warren RF: The effect of joint-compressive load and quadriceps muscle force on knee motion in the intact and anterior cruciate ligament-sectioned knee. Am J Sports Med, 1994, 22: 105-112. [Medline] [CrossRef]

11) Ross MD, Denegar CR, Winzenried JA: Implementation of open and closed kinetic chain quadriceps strengthening exercises after anterior cruciate ligament reconstruction. J Strength Cond Res, 2001, 15: 466-473. [Medline]

12) Mikkelsen C, Werner S, Eriksson E: Closed kinetic chain alone compared to combined open and closed kinetic chain exercises for quadriceps strengthening after anterior cruciate ligament reconstruction with respect to return to sports: a prospective matched follow-up study. Knee Surg Sports Traumatol Arthrosc, 2000, 8: 337-342. [Medline] [CrossRef]

13) Tagesson S, Oberg B, Good L, et al.: A comprehensive rehabilitation program with quadriceps strengthening in closed versus open kinetic chain exercise in patients with anterior cruciate ligament deficiency: a randomized clinical trial evaluating dynamic tibial translation and muscle function. Am J Sports Med, 2008, 36: 298-307. [Medline] [CrossRef]

14) Williams GN, Snyder-Mackler L, Barrance PJ, et al.: Quadriceps femoris muscle morphology and function after ACL injury: a differential response in copers versus non-copers. J Biomech, 2005, 38: 685-693. [Medline] [CrossRef]

15) Konishi Y, Fukubayashi T: Relationship between muscle volume and muscle torque of the hamstrings after anterior cruciate ligament reconstruction. J Sci Med Sport, 2010, 13: 101-105. [Medline] [CrossRef]

16) Lautamies R, Harilainen A, Kettunen J, et al.: Isokinetic quadriceps and hamstring muscle strength and knee function 5 years after anterior cruciate ligament reconstruction: comparison between bone-patellar tendon-bone and hamstring tendon autografts. Knee Surg Sports Traumatol Arthrosc, 2008, 16: 1009-1016. [Medline] [CrossRef] 